\title{
Systematic review and meta-analysis of the efficacy of breast conservation therapy followed by radiotherapy in four breast cancer subtypes
}

\author{
Xin-Bin Pan ${ }^{1}$, Rou-Jun Chen ${ }^{1}$, Shi-Ting Huang ${ }^{1}$, Yan-Ming Jiang ${ }^{1}$ and Xiao-Dong \\ $\mathrm{Zhu}^{1}$ \\ ${ }^{1}$ Department of Radiation Oncology, Cancer Hospital of Guangxi Medical University, Nanning, Guangxi 530021, P.R. China \\ Correspondence to: Xiao-Dong Zhu, email: zhuxiaodonggx@163.com \\ Keywords: breast cancer, molecular subtypes, breast conservation therapy, radiotherapy \\ Received: September 30, $2016 \quad$ Accepted:May 08, $2017 \quad$ Published: May 24, 2017 \\ Copyright: Pan et al. This is an open-access article distributed under the terms of the Creative Commons Attribution License 3.0 (CC BY 3.0), \\ which permits unrestricted use, distribution, and reproduction in any medium, provided the original author and source are credited.
}

\section{ABSTRACT}

The different molecular subtypes of breast cancer are associated with distinct outcomes. We assessed the efficacy of breast conservation therapy (BCT) followed by radiotherapy for patients with different breast cancer subtypes. We searched the MEDLINE, EMBASE, and Cochrane Library databases to identify studies published prior to April 30, 2016 that assessed the efficacy of BCT followed by radiotherapy in breast cancer patients with different molecular subtypes. A meta-analysis of seven studies that included 3,798 luminal A, 770 luminal B, 344 human epidermal growth factor receptor 2 (Her-2), and 767 triple-negative breast cancer (TNBC) patients was performed. The pooled odds ratio [OR] for local relapse-free survival in luminal A compared to Her-2 patients was $0.1960(95 \%$ confidence interval $[\mathrm{CI}]: 0.0440-0.8728, p=0.0325)$ at 5 years and 0.2592 (95\% CI: $0.1301-0.5167, p=0.0001)$ at 10 years. The pooled OR for local-regional relapse-free survival in luminal A compared to TNBC patients was 0.1381 (95\% CI: $0.0565-0.3374, p=0.0000)$ at 5 years and $0.1221(95 \% \mathrm{CI}: 0.0182-0.8192$, $p=\mathbf{0 . 0 3 0 4}$ ) at 10 years. Thus, the rate of local-regional control is higher in luminal $A$ patients than in Her-2 or TNBC patients.

\section{INTRODUCTION}

Breast conservation therapy (BCT) followed by radiotherapy is the standard of care for early-stage breast cancer. Previous studies have evaluated the outcomes of early-stage breast cancer patients without distinguishing between subtypes. However, breast cancer is a heterogeneous disease characterized by a wide spectrum of clinical, pathological, and molecular features [1,2]. Importantly, the molecular subtypes can predict therapeutic response and prognosis.

Several studies have suggested that luminal A breast cancer has the best prognosis, whereas human epidermal growth factor receptor 2 (Her-2) and triple-negative breast cancer (TNBC) have higher rates of local recurrence [3-6]. However, other studies have reported no differences in pairwise comparisons between molecular subtypes $[7,8]$. Because there is a low risk of local recurrence for early-stage breast cancer ( $\leq 5 \%$ at 5 years) [9], it is difficult to assess the association between molecular subtypes and local control.
We performed a systematic review and meta-analysis to evaluate the efficacy of BCT followed by radiotherapy for the treatment of the four different molecular subtypes of breast cancer: luminal A, luminal B, Her-2, and TNBC.

\section{RESULTS}

Study selection and characteristics

The study evaluation process is shown in Figure 1. A total of 1,232 titles were reviewed. Seven studies were selected for our meta-analysis [7, 8, 10-14], which included 3,798 luminal A, 770 luminal B, 344 Her-2, and 767 TNBC patients. The study characteristics are summarized in Table 1.

Quality assessment

The methodological quality of the included studies is shown in Table 2. An independent assessment of outcome parameters was performed in two studies $[8,13]$. Outcome 
parameters were unclear in five studies [7, 10-12, 14]. One study did not have clearly defined outcomes [12].

\section{Meta-analysis}

The pooled odds ratios [ORs] for patients with the different molecular subtypes who were treated with BCT followed by radiotherapy are shown in Table 3 . The analysis of study heterogeneity and publication bias are also presented in Table 3.

The pooled OR for 5-year LFS for patients with luminal A compared to luminal B, Her-2, and TNBC was 0.5221 (95\% confidence interval [95\% CI]: 0.2815-0.9684, p $=0.0392), 0.1960$ (95\% CI: $0.0440-0.8728, \mathrm{p}=0.0325)$, and 0.1731 (95\% CI: 0.0674-0.4444, $\mathrm{p}=0.0003)$, respectively. The pooled OR for 10-year LFS for patients with luminal A compared to Her-2 breast cancer was 0.2592 (95\% CI:
$0.1301-0.5167, \mathrm{p}=0.0001)$. The pooled OR for 10-year LFS for patients with luminal B compared to Her-2 breast cancer was 0.4434 (95\% CI: 0.2200-0.8938, p =0.0230).

The pooled OR for 5-year LRFS for patients with luminal A compared to Her-2 and TNBC was 0.1320 (95\% CI: $0.0310-0.5613, \mathrm{p}=0.0061)$ and 0.1381 (95\% CI: $0.0565-$ $0.3374, p=0.0000)$, respectively. The pooled OR for 10 -year LRFS for patients with luminal A compared to TNBC was 0.1221 (95\% CI: $0.0182-0.8192, p=0.0304)$. There were no differences in pairwise comparisons between the other groups.

\section{DISCUSSION}

The risk of local recurrence risk in patients with early-stage breast cancer is primarily assessed based on
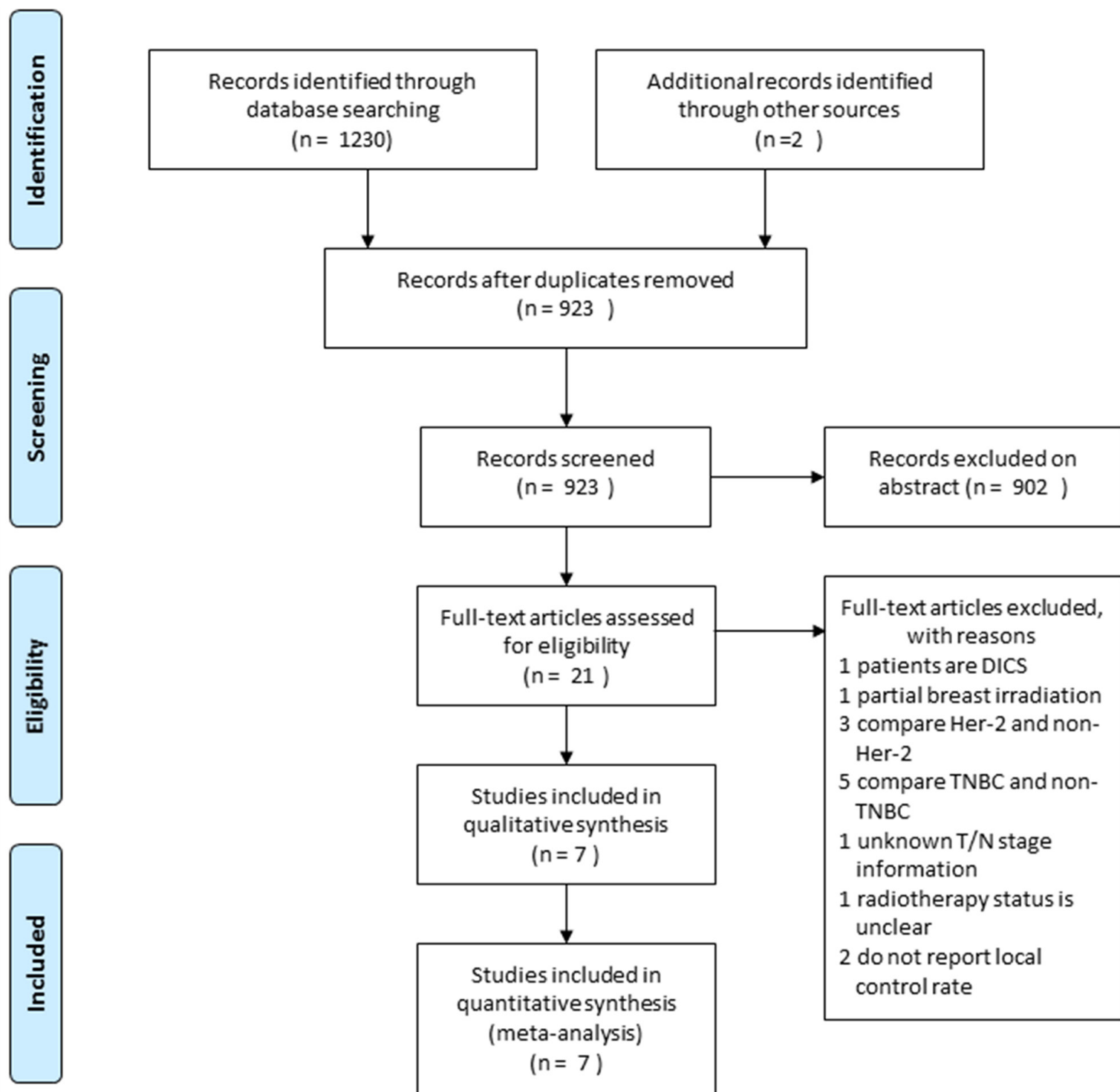

(meta-analysis)

$(n=7)$

Figure 1: Flow chart depicting the study selection process. 
Table 1: Study characteristics

\begin{tabular}{|c|c|c|c|c|c|c|c|c|c|c|c|c|c|c|c|}
\hline \multirow[t]{2}{*}{ Study } & \multirow{2}{*}{$\begin{array}{l}\text { Enrollment } \\
\text { period }\end{array}$} & \multicolumn{5}{|c|}{ Population } & \multirow[t]{2}{*}{ Age (years) } & \multirow{2}{*}{$\begin{array}{c}\text { Follow-up } \\
\text { (months) }\end{array}$} & \multirow[t]{2}{*}{ RT } & \multirow[t]{2}{*}{ CT } & \multirow[t]{2}{*}{ HT } & \multicolumn{4}{|c|}{ Surgery } \\
\hline & & $\begin{array}{c}\text { Luminal } \\
\mathrm{A}\end{array}$ & $\begin{array}{c}\text { Luminal } \\
\text { B }\end{array}$ & Her-2 & TNBC & Total & & & & & & T stage & N stage & Grade 3 & $\underset{(+)}{\operatorname{Margin}}$ \\
\hline Arvold, 2011, USA & $1997-2006$ & $\begin{array}{c}1103 \\
(76.92 \%)\end{array}$ & $\begin{array}{c}105 \\
(7.32 \%)\end{array}$ & $\begin{array}{c}55 \\
(3.84 \%)\end{array}$ & $\begin{array}{c}171 \\
(11.92 \%)\end{array}$ & 1434 & $\geq 5547.0 \%$ & median: 85 & median: $61 \mathrm{~Gy}$ & $\begin{array}{c}660 \\
(46.03 \%)\end{array}$ & $\begin{array}{c}1104 \\
(76.99 \%)\end{array}$ & T3 $0.8 \%$ & N3 1.0\% & $30.5 \%$ & $2.3 \%$ \\
\hline Demirci, 2012, USA & $1985-2005$ & $\begin{array}{c}295 \\
(66.59 \%)\end{array}$ & $\begin{array}{c}75 \\
(16.93 \%)\end{array}$ & $\begin{array}{c}17 \\
(3.84 \%)\end{array}$ & $\begin{array}{c}56 \\
(12.64 \%)\end{array}$ & 443 & median: 56 & median: 118 & median: $62 \mathrm{~Gy}$ & $\begin{array}{c}66 \\
(14.90 \%)\end{array}$ & $\begin{array}{c}204 \\
(46.05 \%)\end{array}$ & $\mathrm{T} 1-2$ & N0-1 & $\mathrm{nc}$ & $\mathrm{nc}$ \\
\hline $\begin{array}{l}\text { Hattangadi-Gluth, 2011, } \\
\text { USA }\end{array}$ & $1998-2003$ & $\begin{array}{c}937 \\
(76.61 \%)\end{array}$ & $\begin{array}{c}98 \\
(8.01 \%)\end{array}$ & $\begin{array}{c}52 \\
(4.25 \%)\end{array}$ & $\begin{array}{c}136 \\
(11.12 \%)\end{array}$ & 1223 & median: 55 & median: 70.4 & median: $60 \mathrm{~Gy}$ & $\begin{array}{c}558 \\
(45.63 \%)\end{array}$ & $\begin{array}{c}942 \\
(77.02 \%)\end{array}$ & T1-2 & N3 1.1\% & $31.6 \%$ & $3.9 \%$ \\
\hline Sanpaolo, 2011, Italy & $2000-2008$ & $\begin{array}{c}361 \\
(46.64 \%)\end{array}$ & $\begin{array}{c}124 \\
(16.02 \%)\end{array}$ & $\begin{array}{c}134 \\
(17.31 \%)\end{array}$ & $\begin{array}{c}155 \\
(20.03 \%)\end{array}$ & 774 & median: 55 & median: 59 & median: $60 \mathrm{~Gy}$ & $\begin{array}{c}328 \\
(42.38 \%)\end{array}$ & $\begin{array}{c}186 \\
(24.03 \%)\end{array}$ & T1-2 & N0-2 & $26.9 \%$ & $9.0 \%$ \\
\hline Wong, 2011, Singapore & 1989-2007 & $\begin{array}{c}247 \\
(59.81 \%)\end{array}$ & $\begin{array}{c}76 \\
(18.40 \%)\end{array}$ & $\begin{array}{c}34 \\
(8.23 \%)\end{array}$ & $\begin{array}{c}56 \\
(13.56 \%)\end{array}$ & 413 & median: 49 & median: 72 & median: $60 \mathrm{~Gy}$ & $\begin{array}{c}194 \\
(46.97 \%)\end{array}$ & $\begin{array}{c}369 \\
(89.35 \%)\end{array}$ & T3 $0.4 \%$ & $\mathrm{nc}$ & $30.7 \%$ & $4.8 \%$ \\
\hline Millar, 2009, Australia & $1996-2003$ & $\begin{array}{c}394 \\
(79.12 \%)\end{array}$ & $\begin{array}{c}23 \\
(4.62 \%)\end{array}$ & $\begin{array}{c}13 \\
(2.61 \%)\end{array}$ & $\begin{array}{c}68 \\
(13.65 \%)\end{array}$ & 498 & median: 61 & median: 84 & 50/61 Gy & $\begin{array}{c}117 \\
(23.49 \%)\end{array}$ & $\begin{array}{c}223 \\
(44.78 \%)\end{array}$ & T3 $0.2 \%$ & N3 $0.4 \%$ & $29.1 \%$ & $\mathrm{nc}$ \\
\hline Bane, 2014, Canada & 1993-1996 & $\begin{array}{c}461 \\
(51.57 \%)\end{array}$ & $\begin{array}{c}269 \\
(30.09 \%)\end{array}$ & $\begin{array}{c}39 \\
(4.36 \%)\end{array}$ & $\begin{array}{c}125 \\
(13.98 \%)\end{array}$ & 894 & $\geq 5073.6 \%$ & median: 144 & $42.5 / 50 \mathrm{~Gy}$ & $\begin{array}{c}110 \\
(12.30 \%)\end{array}$ & $\begin{array}{c}384 \\
(42.95 \%)\end{array}$ & $\mathrm{T} 1-2$ & No & $20.0 \%$ & $\mathrm{nc}$ \\
\hline
\end{tabular}

RT: radiotherapy; CT: chemotherapy; HT: hormone therapy; nc: not clear.

Table 2: Methodology quality assessment

\begin{tabular}{|c|c|c|c|c|c|c|c|}
\hline \multirow[t]{2}{*}{ Criteria } & \multicolumn{7}{|c|}{ Studies } \\
\hline & Arvold & Demirci & Hattangadi-Gluth & Sanpaolo & Wong & Millar & Bane \\
\hline Clear definition of study population & $\sqrt{ }$ & $\sqrt{ }$ & $\sqrt{ }$ & $\sqrt{ }$ & $\sqrt{ }$ & $\sqrt{ }$ & $\sqrt{ }$ \\
\hline Clear definition of outcomes and outcome assessment & $\sqrt{ }$ & $\times$ & $\sqrt{ }$ & $\sqrt{ }$ & $\sqrt{ }$ & $\sqrt{ }$ & $\sqrt{ }$ \\
\hline Independent assessment of outcome parameters & $?$ & $?$ & $\sqrt{ }$ & $?$ & $?$ & $\sqrt{ }$ & $?$ \\
\hline Sufficient duration of follow-up & $\sqrt{ }$ & $\sqrt{ }$ & $\sqrt{ }$ & $\sqrt{ }$ & $\sqrt{ }$ & $\sqrt{ }$ & $\sqrt{ }$ \\
\hline No selective loss during follow-up & $\sqrt{ }$ & $\sqrt{ }$ & $\sqrt{ }$ & $\sqrt{ }$ & $\sqrt{ }$ & $\sqrt{ }$ & $\sqrt{ }$ \\
\hline Important confounders and prognostic factors identified & $\sqrt{ }$ & $\sqrt{ }$ & $\sqrt{ }$ & $\sqrt{ }$ & $\sqrt{ }$ & $\sqrt{ }$ & $\sqrt{ }$ \\
\hline
\end{tabular}

$\sqrt{ }$ : yes; $\times$ : no; ?: not clear.

clinicopathological factors. We demonstrated that patients with the luminal A subtype have a better prognosis than those with the Her-2 subtype following BCT and radiotherapy. Thus, the different molecular subtypes are associated with distinct local control rates and can predict prognosis.

Although breast cancer patients are widely classified into the luminal A, luminal B, Her-2, and TNBC molecular subtypes in clinical practice $[6,15]$, these subtypes are only an approximation of the underlying genotype-based subtypes. A previous study suggested that a fraction of luminal $B$ patients were misclassified as luminal A, because only 30 $50 \%$ of patients classified as luminal B by genotyping were Her-2+ [6]. However, genetic analysis is often impractical in clinical practice because of the time and expense required. Therefore, clinicians routinely make treatment decisions based on classic prognostic factors.

The overall quality of the studies in our meta-analysis was moderate-to-high. The independent assessment of outcome parameters was unclear in five studies [7, 10-12, 14], which was the main source of bias in our analysis. However, independent assessment was not necessarily needed for the included studies because local recurrence is an objective outcome that is defined by pathology and imaging.

Our meta-analysis suggests that Her-2 patients have increased odds of 5- and 10-year LFS compared to luminal A patients. Trastuzumab is the preferred treatment for Her-2+ (luminal B and Her-2) patients. It has been shown to improve overall survival in Her-2+ patients with early-stage breast cancer [16]. However, local recurrence was not assessed [17, 18]. Sanpaolo et al. [7] reported similar local control rates for Her-2 and luminal A patients treated with trastuzumab. However, some studies have reported that trastuzumab did not affect the rate of local relapse in Her-2 patients, and there was no difference in local recurrence between patients with the Her-2 and luminal A subtypes [8, 19, 20]. Only two studies included in our meta-analysis analyzed patients treated with trastuzumab $(87.3 \%$ had Her- 2 type breast cancer in the Sanpaolo et al. study [7] and one had Her-2 breast cancer in the Wong et al. study [14]). Trastuzumab therapy was not administered to Her-2 patients in the other five studies [8, 10-13]. The observed differences in LFS between Her-2 and luminal A patients in our meta-analysis could be 
Table 3: Pooled odds ratios for BCT followed by radiotherapy on different molecular subtypes of breast cancer

\begin{tabular}{|c|c|c|c|c|c|c|c|c|c|c|c|}
\hline \multirow[t]{2}{*}{ Outcome } & \multirow[t]{2}{*}{ Comparison } & \multicolumn{4}{|c|}{ Meta-analysis } & \multicolumn{3}{|c|}{ Heterogeneity test } & \multirow[t]{2}{*}{ Model } & \multicolumn{2}{|c|}{$\begin{array}{l}\text { Publication bias } \\
\quad(p \text { Value) }\end{array}$} \\
\hline & & OR & $95 \% \mathrm{CI}$ & z Value & p Value & $\mathbf{I}^{2}$ & q Value & p Value & & Begg's test & Egger's test \\
\hline \multicolumn{12}{|c|}{ 5-year LFS } \\
\hline & Luminal A vs. luminal B & 0.5221 & $0.2815-0.9684$ & 2.06 & 0.0392 & 0.00 & 3.39 & 0.4955 & Fixed & 0.8065 & 0.7773 \\
\hline & Luminal A vs. Her-2 & 0.1960 & $0.0440-0.8728$ & 2.14 & 0.0325 & 79.98 & 19.98 & 0.0005 & Random & 0.8065 & 0.7624 \\
\hline & Luminal A vs. TNBC & 0.1731 & $0.0674-0.4444$ & 3.65 & 0.0003 & 73.14 & 14.89 & 0.0049 & Random & 0.0864 & 0.2480 \\
\hline & luminal B vs. Her-2 & 0.4306 & $0.0741-2.5006$ & 0.94 & 0.3478 & 72.05 & 14.31 & 0.0064 & Random & 0.8065 & 0.1702 \\
\hline & luminal B vs. TNBC & 0.3588 & $0.0872-1.4755$ & 1.42 & 0.1554 & 69.43 & 13.09 & 0.0109 & Random & 1.0000 & 0.0232 \\
\hline & Her-2 vs. TNBC & 0.9483 & $0.5497-1.6357$ & 0.19 & 0.8486 & 24.92 & 5.33 & 0.2553 & Fixed & 0.4624 & 0.2496 \\
\hline \multicolumn{12}{|c|}{ 5-year LRFS } \\
\hline & Luminal A vs. luminal B & 0.4670 & $0.0610-3.5768$ & 0.73 & 0.4635 & - & - & - & Fixed & - & - \\
\hline & Luminal A vs. Her-2 & 0.1320 & $0.0310-0.5613$ & 2.74 & 0.0061 & - & - & - & Fixed & - & - \\
\hline & Luminal A vs. TNBC & 0.1381 & $0.0565-0.3374$ & 4.34 & 0.0000 & - & - & - & Fixed & - & - \\
\hline & luminal B vs. Her-2 & 0.2826 & $0.0283-2.8247$ & 1.08 & 0.2820 & - & - & - & Fixed & - & - \\
\hline & luminal B vs. TNBC & 0.2957 & $0.0400-2.1857$ & 1.19 & 0.2325 & - & - & - & Fixed & - & - \\
\hline & Her-2 vs. TNBC & 1.0462 & $0.2586-4.2316$ & 0.06 & 0.9495 & - & - & - & Fixed & - & - \\
\hline \multicolumn{12}{|c|}{ 10-year LFS } \\
\hline & Luminal A vs. luminal B & 0.5860 & $0.3422-1.0037$ & 1.95 & 0.0516 & 0.00 & 0.27 & 0.6048 & Fixed & 1.0000 & - \\
\hline & Luminal A vs. Her-2 & 0.2592 & $0.1301-0.5167$ & 3.84 & 0.0001 & 0.00 & 0.42 & 0.5177 & Fixed & 1.0000 & - \\
\hline & Luminal A vs. TNBC & 0.6887 & $0.2341-2.0261$ & 0.68 & 0.4981 & 62.39 & 2.66 & 0.1030 & Random & 1.0000 & - \\
\hline & luminal B vs. Her-2 & 0.4434 & $0.2200-0.8938$ & 2.27 & 0.0230 & 0.00 & 0.80 & 0.3717 & Fixed & 1.0000 & - \\
\hline & luminal B vs. TNBC & 1.6545 & $0.7414-3.6919$ & 1.23 & 0.2189 & 0.00 & 0.56 & 0.4555 & Fixed & 1.0000 & - \\
\hline & Her- 2 vs. TNBC & 2.6296 & $\begin{array}{l}0.4828- \\
14.3219\end{array}$ & 1.12 & 0.2636 & 57.09 & 2.33 & 0.1269 & Random & 1.0000 & - \\
\hline \multicolumn{12}{|c|}{ 10-year LRFS } \\
\hline & Luminal A vs. luminal B & 0.7707 & $0.2201-2.6986$ & 0.41 & 0.6838 & 0.00 & 0.53 & 0.4667 & Fixed & 1.0000 & - \\
\hline & Luminal A vs. Her-2 & 0.3354 & $0.0980-1.1484$ & 1.74 & 0.0819 & 0.00 & 0.04 & 0.8512 & Fixed & 1.0000 & - \\
\hline & Luminal A vs. TNBC & 0.1221 & $0.0182-0.8192$ & 2.17 & 0.0304 & 86.40 & 7.35 & 0.0067 & Random & 1.0000 & - \\
\hline & luminal B vs. Her-2 & 0.5652 & $0.0899-3.5525$ & 0.61 & 0.5430 & - & - & - & Fixed & - & - \\
\hline & luminal B vs. TNBC & 0.1502 & $0.0062-3.6671$ & 1.16 & 0.2449 & 76.24 & 4.21 & 0.0402 & Random & 1.0000 & - \\
\hline & Her-2 vs. TNBC & 0.4448 & $0.0489-4.0442$ & 0.72 & 0.4719 & 54.42 & 2.19 & 0.1386 & Random & 1.0000 & - \\
\hline
\end{tabular}

explained by the treatment of Her-2 patients with adjuvant trastuzumab therapy.

A previous meta-analysis demonstrated that the 5-year local control rate of TNBC patients was similar to that of non-TNBC patients [21]. In this study, TNBC patient outcomes were not analyzed according to subtype. Our meta-analysis suggests that TNBC patients had lower LRFS compared to luminal A patients. The increased risk of local-regional recurrence in TNBC patients may be correlated with the aggressive clinicopathological features and ineffectiveness of endocrine therapy or trastuzumab. There is insufficient data regarding the relationship between luminal B, Her-2, and TNBC and the risk of local recurrence. Our meta-analysis indicated there were no differences between patients with luminal B, Her-2, and TNBC.

Most local recurrences of breast cancer occur during the first 5 years following BCT and radiotherapy [22]. Our meta-analysis suggests that the local-regional control rate is higher in patients with the luminal $\mathrm{A}$ compared to Her-2 and TNBC. However, it is unclear whether local recurrence reflected inadequate patient selection/inadequate local treatment or aggressive disease. Her-2 and TNBC are associated with 
substantially higher rates of local-regional recurrence, suggesting that these subtypes are more aggressive than the luminal A subtype. Trastuzumab therapy for Her-2 patients may reduce the rate of local-regional recurrence. There are currently no effective therapies for TNBC.

Our meta-analysis had several limitations. First, the surgical approach and treatments (e.g. chemotherapy and hormone therapy) differed between studies. Some studies included patients with a positive margin and stage $\mathrm{T} 3 / \mathrm{N} 3$ disease. The percent of patients who received chemotherapy and hormone therapy varied between studies. Second, our sample size was limited. This is because there is a low risk of local recurrence in earlystage breast cancer patients.

In conclusion, breast cancer molecular subtypes predict outcomes and treatment response in early-stage breast cancer patients treated with BCT followed by radiotherapy. Our results should be validated in patients with Her-2+ breast cancer treated with trastuzumab.

\section{MATERIALS AND METHODS}

\section{Study design}

Our study was performed in accordance with the Meta-analysis of Observational Studies in Epidemiology [23] and PRISMA guidelines [24].

\section{Selection criteria}

Studies that assessed the efficacy of BCT followed by radiotherapy in breast cancer patients were reviewed. The inclusion criteria were (1) invasive breast cancer treated with BCT followed by radiotherapy, (2) complete data on breast cancer molecular subtype, and (3) at least one outcome report (i.e. local relapse-free survival [LFS]), local-regional relapse-free survival (LRFS), or sufficient information to calculate LFS or LRFS. The exclusion criteria were (1) ductal carcinoma in situ, (2) incomplete data on molecular subtype, and (3) incomplete data on BCT or radiotherapy.

Breast cancer patients were classified into the following four groups based on estrogen receptor (ER), progesterone receptor (PR), and Her-2 status: luminal A (ER+ and/or PR+ and Her-2-), luminal B (ER+ and/or $\mathrm{PR}+$, and Her-2+), Her-2 (ER- and PR-, and Her-2+), and TNBC (ER-, PR-, and Her-2-) [6, 15]. Because BCT and radiotherapy mainly provide local control, the endpoints of our meta-analysis were LFS and LRFS.

\section{Data sources and queries}

We searched the MEDLINE, EMBASE, and Cochrane Library databases to identify relevant studies completed before April 30, 2016. Search terms included 'breast cancer', 'breast conservation therapy', 'radiotherapy', and 'molecular subtype'. Article reference lists were also reviewed to identify additional studies. No language restrictions were imposed.

\section{Study selection and quality assessment}

Study selection, data extraction, and quality assessment were performed by two independent investigators. Differences were resolved through discussion with a third investigator. Quality assessment was performed according to Hayden et al. [25]. Study quality and risk of bias were assessed based on the following criteria: (1) clear definition of study population, (2) clear definition of outcomes and outcome assessment, (3) independent assessment of outcome parameters, (4) sufficient duration of follow-up, (5) no selective loss during follow-up, and (6) important confounders and prognostic factors identified.

\section{Statistical analysis}

Cochran Q tests and $\mathrm{I}^{2}$ statistics were used to assess study heterogeneity, where a $p<0.05$ and $\mathrm{I}^{2}>50 \%$ were indicative of significant heterogeneity. A random-effects model was selected if heterogeneity was present and a fixed-effects model was selected in the absence of significant heterogeneity. Publication bias was evaluated using a funnel plot of trial effect size vs. standard error $[26,27]$. All statistical analyses were performed using STATA version 12.0 (STATA, College Station, TX, USA).

\section{Abbreviations}

BCT: breast conservation therapy; Her-2: human epidermal growth factor receptor 2; OR: odds ratio; LFS: local relapse-free survival; LRFS: local-regional relapsefree survival; ER: estrogen receptor; PR: progesterone receptor.

\section{Author contributions}

PXB and ZXD contributed to the conception of the study; CRJ and HST contributed to manuscript preparation; PXB and CRJ performed the data analyses; HST and JYM helped perform the analysis with constructive discussions.

\section{ACKNOWLEDGMENTS}

None. 


\section{CONFLICTS OF INTEREST}

The authors declare no conflicts of interest.

\section{FUNDING}

No.

\section{REFERENCES}

1. Sorlie T. Molecular portraits of breast cancer: tumour subtypes as distinct disease entities. Eur J Cancer. 2004; 40: 2667-75. doi: 10.1016/j.ejca.2004.08.021.

2. Perou CM, Sorlie T, Eisen MB, van de Rijn M, Jeffrey SS, Rees CA, Pollack JR, Ross DT, Johnsen H, Akslen LA, Fluge O, Pergamenschikov A, Williams C, et al. Molecular portraits of human breast tumours. Nature. 2000; 406: 74752. doi: 10.1038/35021093.

3. Sorlie T, Perou CM, Tibshirani R, Aas T, Geisler S, Johnsen $\mathrm{H}$, Hastie T, Eisen MB, van de Rijn M, Jeffrey SS, Thorsen T, Quist H, Matese JC, et al. Gene expression patterns of breast carcinomas distinguish tumor subclasses with clinical implications. Proc Natl Acad Sci U S A. 2001; 98: 10869 74. doi: 10.1073/pnas.191367098.

4. Sorlie T, Tibshirani R, Parker J, Hastie T, Marron JS, Nobel A, Deng S, Johnsen H, Pesich R, Geisler S, Demeter J, Perou CM, Lonning PE, et al. Repeated observation of breast tumor subtypes in independent gene expression data sets. Proc Natl Acad Sci U S A. 2003; 100: 8418-23. doi: 10.1073/pnas.0932692100.

5. Sotiriou C, Neo SY, McShane LM, Korn EL, Long PM, Jazaeri A, Martiat P, Fox SB, Harris AL, Liu ET. Breast cancer classification and prognosis based on gene expression profiles from a population-based study. Proc Natl Acad Sci U S A. 2003; 100: 10393-8. doi: 10.1073/ pnas. 1732912100.

6. Carey LA, Perou CM, Livasy CA, Dressler LG, Cowan D, Conway K, Karaca G, Troester MA, Tse CK, Edmiston S, Deming SL, Geradts J, Cheang MC, et al. Race, breast cancer subtypes, and survival in the Carolina Breast Cancer Study. JAMA. 2006; 295: 2492-502. doi: 10.1001/jama.295.21.2492.

7. Sanpaolo P, Barbieri V, Genovesi D. Prognostic value of breast cancer subtypes on breast cancer specific survival, distant metastases and local relapse rates in conservatively managed early stage breast cancer: a retrospective clinical study. Eur J Surg Oncol. 2011; 37: 876-82. doi: 10.1016/j. ejso.2011.07.001.

8. Millar EK, Graham PH, O'Toole SA, McNeil CM, Browne L, Morey AL, Eggleton S, Beretov J, Theocharous C, Capp A, Nasser E, Kearsley JH, Delaney G, et al. Prediction of local recurrence, distant metastases, and death after breastconserving therapy in early-stage invasive breast cancer using a five-biomarker panel. J Clin Oncol. 2009; 27: 47018. doi: 10.1200/JCO.2008.21.7075.
9. Wapnir IL, Anderson SJ, Mamounas EP, Geyer CE Jr, Jeong JH, Tan-Chiu E, Fisher B, Wolmark N. Prognosis after ipsilateral breast tumor recurrence and locoregional recurrences in five National Surgical Adjuvant Breast and Bowel Project node-positive adjuvant breast cancer trials. J Clin Oncol. 2006; 24: 2028-37. doi: 10.1200/ JCO.2005.04.3273.

10. Arvold ND, Taghian AG, Niemierko A, Abi Raad RF, Sreedhara M, Nguyen PL, Bellon JR, Wong JS, Smith BL, Harris JR. Age, breast cancer subtype approximation, and local recurrence after breast-conserving therapy. J Clin Oncol. 2011; 29: 3885-91. doi: 10.1200/JCO.2011.36.1105.

11. Bane AL, Whelan TJ, Pond GR, Parpia S, Gohla G, Fyles AW, Pignol JP, Pritchard KI, Chambers S, Levine MN. Tumor factors predictive of response to hypofractionated radiotherapy in a randomized trial following breast conserving therapy. Ann Oncol. 2014; 25: 992-8. doi: 10.1093/annonc/mdu090.

12. Demirci S, Broadwater G, Marks LB, Clough R, Prosnitz LR. Breast conservation therapy: the influence of molecular subtype and margins. Int J Radiat Oncol Biol Phys. 2012; 83: 814-20. doi: 10.1016/j.ijrobp.2011.09.001.

13. Hattangadi-Gluth JA, Wo JY, Nguyen PL, Abi Raad RF, Sreedhara M, Niemierko A, Freer PE, Georgian-Smith D, Bellon JR, Wong JS, Smith BL, Harris JR, Taghian AG. Basal subtype of invasive breast cancer is associated with a higher risk of true recurrence after conventional breastconserving therapy. Int J Radiat Oncol Biol Phys. 2012; 82: 1185-91. doi: 10.1016/j.ijrobp.2011.02.061.

14. Wong FY, Chin FK, Lee KA, Soong YL, Chua ET. Hormone receptors and HER-2 status as surrogates for breast cancer molecular subtypes prognosticate for disease control in node negative Asian patients treated with breast conservation therapy. Ann Acad Med Singapore. 2011; 40: 90-6.

15. Brenton JD, Carey LA, Ahmed AA, Caldas C. Molecular classification and molecular forecasting of breast cancer: ready for clinical application? J Clin Oncol. 2005; 23: 735060. doi: 10.1200/JCO.2005.03.3845.

16. Cameron D, Piccart-Gebhart MJ, Gelber RD, Procter M, Goldhirsch A, de Azambuja E, Castro G Jr, Untch M, Smith I, Gianni L, Baselga J, Al-Sakaff N, Lauer S, et al. 11 years' follow-up of trastuzumab after adjuvant chemotherapy in HER2-positive early breast cancer: final analysis of the HERceptin Adjuvant (HERA) trial. Lancet. 2017; 389: 1195-205. doi: 10.1016/S0140-6736(16)32616-2.

17. Piccart-Gebhart MJ, Procter M, Leyland-Jones B, Goldhirsch A, Untch M, Smith I, Gianni L, Baselga J, Bell R, Jackisch C, Cameron D, Dowsett M, Barrios CH, et al. Trastuzumab after adjuvant chemotherapy in HER2positive breast cancer. N Engl J Med. 2005; 353: 1659-72. doi: 10.1056/NEJMoa052306.

18. Romond EH, Perez EA, Bryant J, Suman VJ, Geyer CE Jr, Davidson NE, Tan-Chiu E, Martino S, Paik S, Kaufman PA, Swain SM, Pisansky TM, Fehrenbacher L, et al. 
Trastuzumab plus adjuvant chemotherapy for operable HER2-positive breast cancer. N Engl J Med. 2005; 353: 1673-84. doi: 10.1056/NEJMoa052122.

19. Buchholz TA, Huang EH, Berry D, Pusztai L, Strom EA, McNeese MD, Perkins GH, Schechter NR, Kuerer HM, Buzdar AU, Valero V, Hunt KK, Hortobagyi GN, et al. Her2/neu-positive disease does not increase risk of locoregional recurrence for patients treated with neoadjuvant doxorubicin-based chemotherapy, mastectomy, and radiotherapy. Int J Radiat Oncol Biol Phys. 2004; 59: 1337-42. doi: 10.1016/j.ijrobp.2004.02.018.

20. Harris EE, Hwang WT, Lee EA, Cengel KA, Feldman MD, Demichele A, Kao G, Solin LJ. The impact of HER-2 status on local recurrence in women with stage I-II breast cancer treated with breastconserving therapy. Breast J. 2006; 12: 431-6. doi: 10.1111/j.1075-122X.2006.00297.x.

21. Pan XB, Qu S, Jiang YM, Zhu XD. Triple negative breast cancer versus non-triple negative breast cancer treated with breast conservation surgery followed by radiotherapy: a systematic review and meta-analysis. Breast Care (Basel). 2015; 10: 413-6. doi: 10.1159/000441436.

22. Clarke M, Collins R, Darby S, Davies C, Elphinstone P, Evans V, Godwin J, Gray R, Hicks C, James S, MacKinnon E, McGale P, McHugh T, et al. Effects of radiotherapy and of differences in the extent of surgery for early breast cancer on local recurrence and 15-year survival: an overview of the randomised trials. Lancet. 2005; 366: 2087-106. doi: 10.1016/S0140-6736(05)67887-7.

23. Stroup DF, Berlin JA, Morton SC, Olkin I, Williamson GD, Rennie D, Moher D, Becker BJ, Sipe TA, Thacker SB. Meta-analysis of observational studies in epidemiology: a proposal for reporting. Meta-analysis Of Observational Studies in Epidemiology (MOOSE) group. JAMA. 2000; 283: 2008-12.

24. Liberati A, Altman DG, Tetzlaff J, Mulrow C, Gotzsche PC, Ioannidis JP, Clarke M, Devereaux PJ, Kleijnen J, Moher D. The PRISMA statement for reporting systematic reviews and meta-analyses of studies that evaluate healthcare interventions: explanation and elaboration. BMJ. 2009; 339: b2700. doi: 10.1136/bmj.b2700.

25. Hayden JA, Cote P, Bombardier C. Evaluation of the quality of prognosis studies in systematic reviews. Ann Intern Med. 2006; 144: 427-37.

26. Egger M, Davey Smith G, Schneider M, Minder C. Bias in meta-analysis detected by a simple, graphical test. BMJ. 1997; 315: 629-34.

27. Begg CB, Mazumdar M. Operating characteristics of a rank correlation test for publication bias. Biometrics. 1994; 50: 1088-101. 